\title{
Current Status of Research on HIV Epidemic, Pathogenesis, Management and Prevention in India
}

\author{
Ramesh S. Paranjape • Madhuri R. Thakar • \\ Manisha V. Ghate $\cdot$ Sheela V. Godbole
}

Received: 18 October 2011/ Accepted: 14 November 2011/Published online: 3 February 2012

(C) The Author(s) 2012. This article is published with open access at Springerlink.com

\begin{abstract}
The Indian HIV epidemic has not reached the predicted proportions even after more than 25 years since the first case of HIV infection was detected in Chennai. An estimated 2.4 million adults were living with HIV in 2009 and an adult prevalence of HIV was $0.3 \%$. The disease burden is geographically diverse and has spread to rural areas also. HIV viruses circulating in India predominantly belong to HIV-1 subtype $\mathrm{C}$ although recombinant strains and HIV-2 infections have been identified. Tuberculosis is the commonest opportunistic infection reported from various parts of the country and HIV-TB co-infection is a public health challenge. Government of India launched free antiretroviral treatment (ART) programme 6 years back which has shown good clinical and immunological response in HIV infected individuals. Though the drug resistance monitoring survey has reported effectiveness of regimen in the programme, adherence remains the key issue for minimizing the drug resistance. In addition to the ongoing prevention efforts, India should be poised to accept and scale up newer preventive tools in a manner acceptable and feasible in our socio-cultural context in order to sustain and consolidate the gains that we have achieved so far.
\end{abstract}

Keywords Human immunodeficiency virus . Epidemiology $\cdot$ Pathogenesis $\cdot$ Management

R. S. Paranjape $(\bowtie) \cdot$ M. R. Thakar · M. V. Ghate ·

S. V. Godbole

National AIDS Research Institute, G-73, MIDC, Bhosari,

P.O. Box 1895, Pune 411 026, India

e-mail: rparanjape@ nariindia.org

\section{Introduction}

The year 1986 marked the beginning of Indian AIDS epidemic with detection of the first HIV infection in Chennai and the first AIDS Case in Mumbai [1-3]. This was followed by the explosive epidemic among intravenous drug users (IDU) in Manipur in 1989 [4, 5]. Since then the HIV epidemic has spread to rural and urban areas, involving highrisk groups as well as the general population. However, the Indian epidemic has not reached the predicted proportions even after more than 25 years since the first case was detected. The HIV disease burden is geographically diverse with some districts showing generalized epidemic with prevalence among ante-natal women being more than $1 \%$ and others with concentrated or low level epidemics.

\section{Epidemiology of HIV Infection in India}

Taking note of the Global HIV situation Indian Council of Medical Research initiated surveys for detection of HIV infection in different parts of India as early as in 1985 [3]. The epidemiologic data on HIV infection in India is now available through multiple sources such as the expanded annual sentinel surveillance among ante-natal women and populations at high risk of HIV infection, the National Family Health Survey-3 (NFHS-3), Behavioural Sentinel Surveillance (BSS) surveys and Integrated Behavioural and Biological Assessment (IBBA) surveys.

Data on national HIV estimates released by the National AIDS Control organization (NACO) in December 2010 reveals a decline in overall adult HIV prevalence from $0.41 \%$ in 2000 to $0.31 \%$ in 2009 with estimated reduction in new (incident) HIV infections of more than $50 \%$ over the last decade. It is estimated that India had approximately 
0.12 million new HIV infections in 2009, as against 0.27 million in 2000. In all, 11 states showed an estimated adult HIV prevalence greater than the national average $(0.31 \%)$. Manipur showed the highest estimated adult HIV prevalence of $1.4 \%$, followed by Andhra Pradesh (0.90\%), Mizoram $(0.81 \%)$, Nagaland $(0.78 \%)$, Karnataka $(0.63 \%)$ and Maharashtra $(0.55 \%)$. Delhi, Orissa, West Bengal, Chhattisgarh \& Pondicherry have shown estimated adult HIV prevalence of $0.28-0.3 \%$. All other states/union territories have lower levels of HIV prevalence (Fig. 1) [6].

The Indian epidemic is primarily driven by unprotected sex in commercial setting [7] in most parts of the country while intravenous drug use is a major driver in the NorthEast. Recently released data have shown a clear decline of HIV prevalence among Female Sex Workers in most of the states. However, the evidence shows that IDU and Men having sex with men (MSM) populations are more vulnerable to HIV with trend of increasing prevalence in many states.

\section{HIV and STIs}

The first data on HIV incidence in high risk populations in India emerged from a prospective cohort of sexually transmitted disease (STD) clinic attendees in Pune. The overall HIV sero-prevalence among STD clinic attendees at screening was found to be $21.2 \%$ (1993-1995) with alarmingly high incidence rates of $9.6 \%$ among male STD patients, and $26.1 \%$ among commercial sex workers [8]. Incidence rate of $4.6 \%$ was reported among women who were not engaged in sex work and did not have any highrisk behaviour of their own [9]. Their only risk factor was being married to a person with high risk behaviour
Fig. 1 State wise estimated adult HIV prevalence in India2009 (Based on NACO) [6]

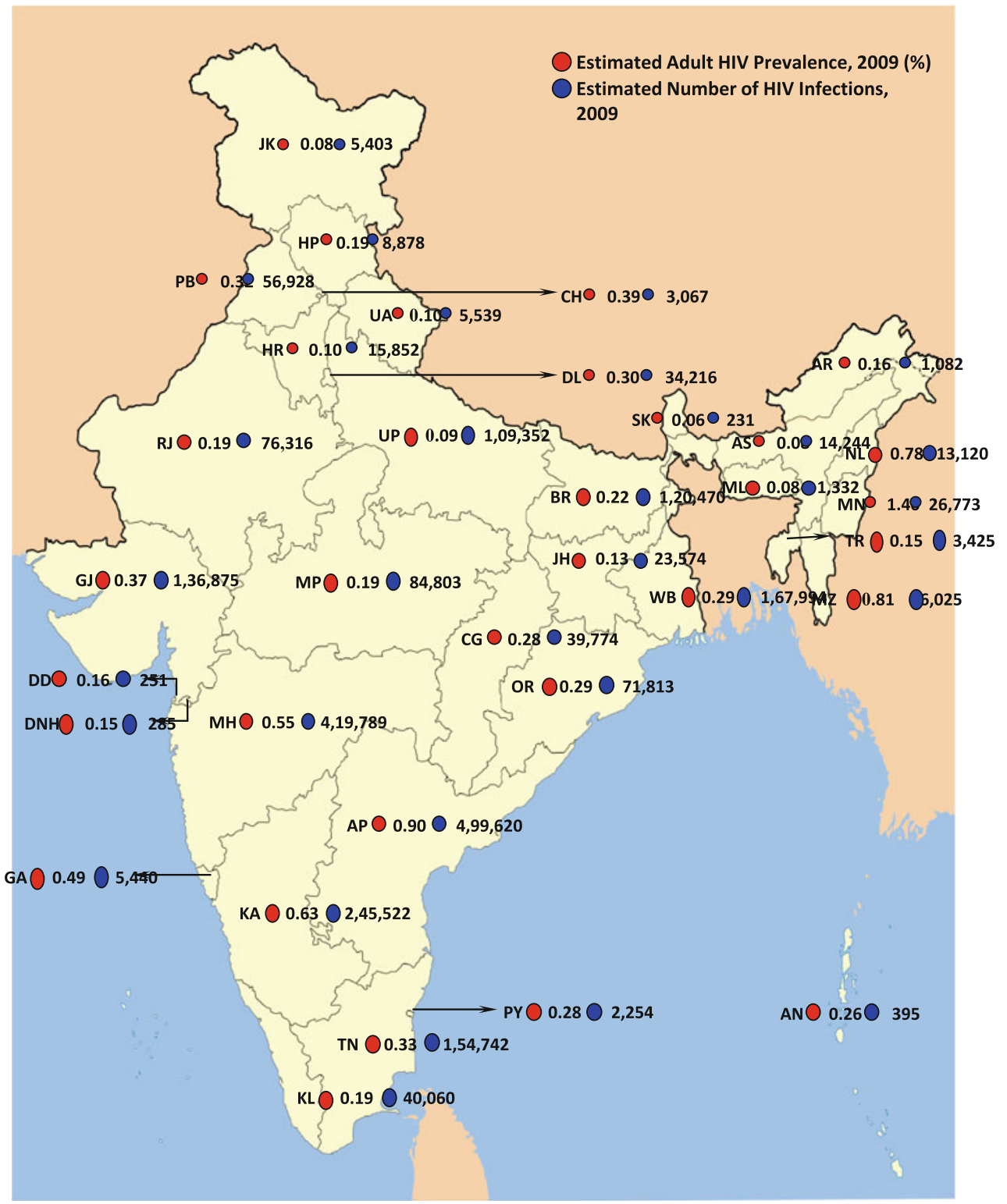


highlighting the need for interventions among women. The cohort studies at NARI also highlighted the role of various other sexually transmitted infections in HIV transmission. Ulcerative and non ulcerative STDs increase the risk of HIV acquisition and incident HSV-2 infection increases the risk of HIV-1 acquisition three times [10] while incident syphilis increases the risk 4.44 times [11]. While these data have highlighted the importance of STI treatment and control for HIV prevention, studies using multiplex PCR techniques for diagnosis of genital ulcers not only demonstrated multiple aetiologies but also supported the use of syndromic treatment in the control program.

Other risks for HIV Infection: Migration, Driving Long Distance Trucks

'Most at Risk Populations' (MARPS) are the populations most vulnerable to HIV like sex workers (both male and female), MSM and IDU. Additionally single male migrants and long distance truck drivers are also more vulnerable and they along with male clients of sex workers and STD patients form the populations that bridge the high risk groups to the general population.

Migration is now increasingly recognised as an important facilitator of the spread of HIV infection in India as well as other parts of the world. Districts in Maharashtra with high in and out migration have also been identified as having high HIV prevalence [12]. Data from IBBA survey round-I conducted among 2,066 long distance truckers in India revealed an HIV prevalence of $4.6 \%$ [13]. The data collected from long distance truck drivers indicated low self-risk perception for HIV (9.9\%), low consistent condom use with non-paid partners (18.6\%) and wives (3\%), low reported exposure to any interventions $(25.6 \%)$ and low levels of ever having taken an HIV test (16.5\%). These observations emphasize the need for strengthening of interventions in this important bridge population.

\section{HIV and Tuberculosis}

Tuberculosis is not a risk factor for HIV infection. However, HIV infected individuals with compromised immune system commonly suffer from tuberculosis. Increasing trend of HIV prevalence was observed among newly diagnosed tuberculosis patients in Pune, from 3.2\% in 1991 to $20.1 \%$ in 1996 [14]. However prevalence of HIV among newly diagnosed Tuberculosis patients varies across the states $[15,16]$. The "lifetime risk" of developing active tuberculosis in immune-competent persons is $5-10 \%$, however in HIV infected individuals there is a $5-15 \%$ "annual risk" of developing active TB disease. There are data indicating chemoprophylaxis for tuberculosis reducing the incidence of active TB in HIV infected individuals.
However various operational issues are still unresolved for inclusion of TB prophylaxis in the programme. Recognizing the association of TB and HIV, the National AIDS Control Programme (NACP) and Revised National Tuberculosis Control Programme (RNTCP) have encouraged the cross referrals to bring TB patients with HIV infection under HIV care programmes.

\section{Transfusion and HIV}

While transfusion transmitted infections have decreased considerably with the focused and intensive blood safety strategy by NACO; persons requiring repeated blood transfusions like haemophiliacs, are still vulnerable to HIV infection and need to be educated about accessing transfusions only from authorized blood banks.

\section{HIV-2 Infection}

In India the HIV-2 infections constitute a very small $(<2 \%)$ proportion of all HIV infections [17, 18], however higher percentages (6\%) have been reported in Mumbai [19]. HIV-2 infection is reported to follow a relatively slow disease progression. Although HIV-2 infections are relatively minor, discriminating between HIV-1 and HIV-2 is critical for initiating anti-retroviral treatment.

\section{Structure of HIV}

HIV is a lentivirus that belongs to the family Retroviridae. The name 'lentivirus' means 'slow virus' because they take long time, often many years to produce any adverse effects in the host. These viruses have single stranded RNA genome and an enzyme called reverse transcriptase.

HIV has an envelope composed of phospholipid bilayer drawn from the host cell membrane and the HIV Env protein gp160; composed of gp120 and gp41. While gp120 is external protein and contains sites that bind CD4 and coreceptors on the surface of human CD4 T cells, gp 41 is membrane bound protein. The viral core or capsid is composed of protein $\mathrm{p} 24$. The layer between the envelope and the capsid i.e., matrix is composed of the protein p17. The bullet-shaped viral capsid contains two positive strands of RNA and the three enzymes required for HIV replication, reverse transcriptase, integrase and protease (Fig. 2).

HIV genome is approximately $9.1 \mathrm{~Kb}$ in size. It has nine genes (structural, regulatory and accessory) and long terminal repeat (LTR) region at either end of the genome (Fig. 3).

The three structural genes gag, pol and env code for the structural proteins for new virion and include Env protein 
Fig. 2 Structure of HIV

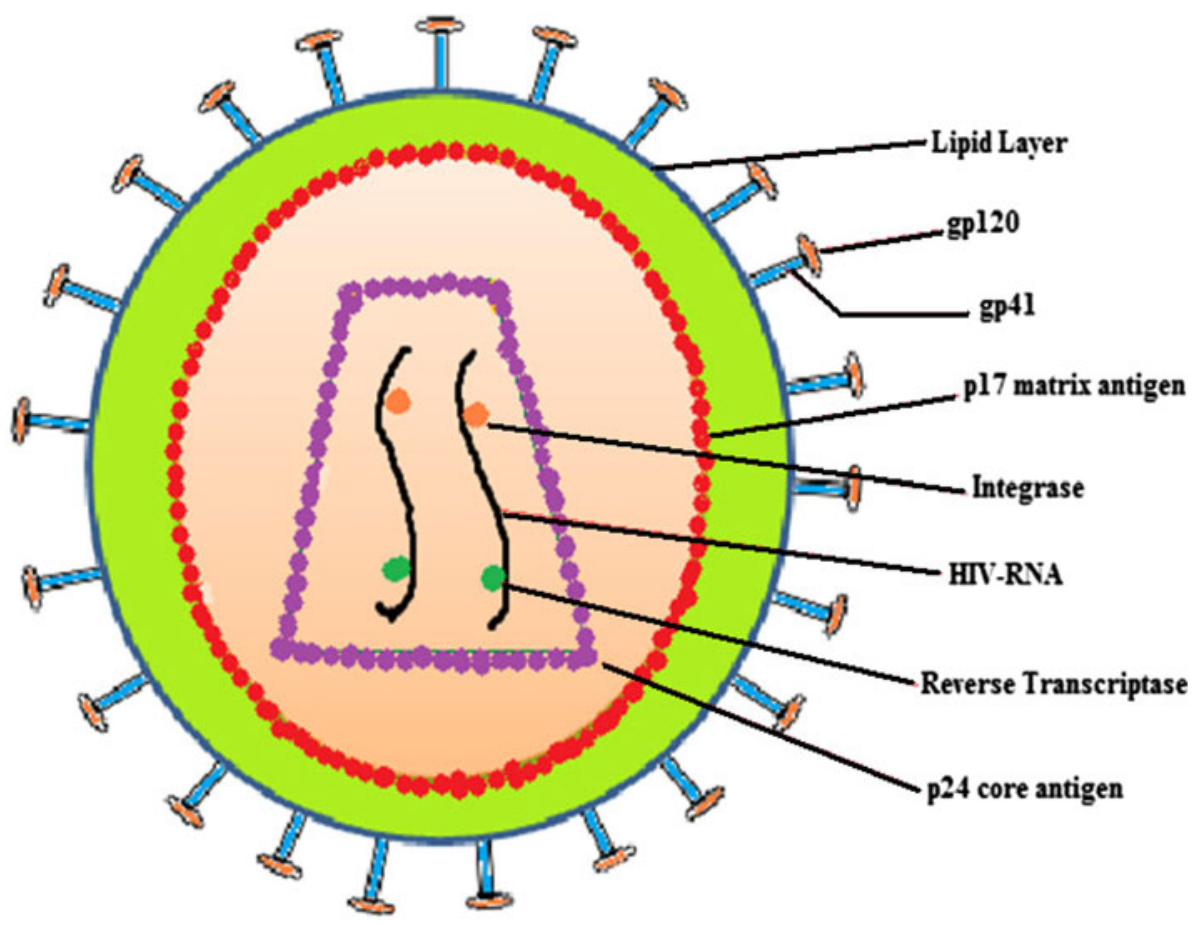

Fig. 3 HIV genome

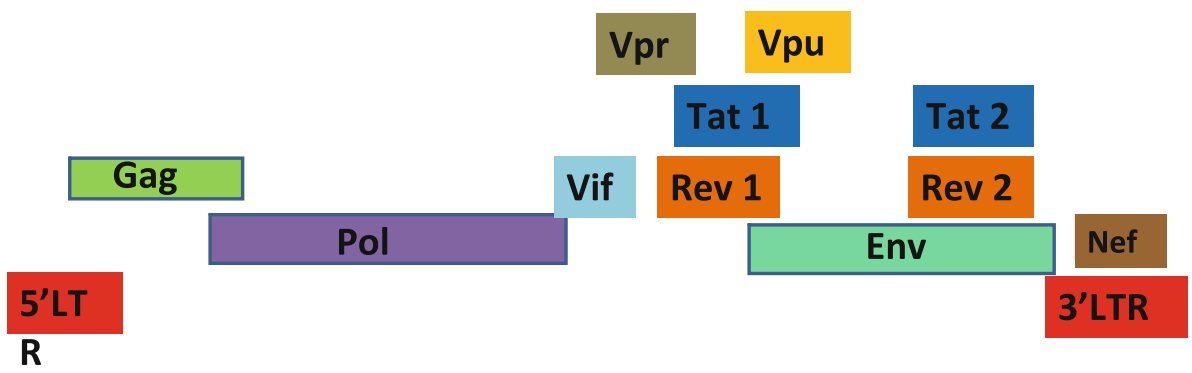

(Env), capsid and matrix proteins (Gag) and enzymes integrase, protease and reverse transcriptase (Pol).

The regulatory genes tat, rev and nef are essential for virus replication.

The accessory genes vif, $v p r$ and $v p u$ (or vpx in the case of HIV-2), are also important in virus replication.

Each strand of HIV RNA contains an RNA sequence called the long terminal repeat (LTR) at both the ends. The LTRs act as switches to control production of new viruses and can be triggered by proteins from either HIV or the host cell (Fig. 3).

HIV-1 is closely related to Simian Immunodeficiency Virus (SIV) prevalent in populations of wild chimpanzees in West-Central Africa and is believed to have been transmitted to humans between 1930 and 1950 .

Due to lack of proof reading ability of Reverse Transcriptase enzyme, HIV shows very high mutation rate. As a result of high mutation rate, HIV-1 virus strains show extreme genetic divergence and have been classified into nine subtypes $(\mathrm{A}-\mathrm{D}, \mathrm{F}, \mathrm{H}-\mathrm{K})$, more than 30 circulating recombinant forms (CRFs) and innumerable unique recombinant forms (URFs). The distribution of subtypes is largely geographically restricted such as HIV-1 Subtype A in Africa, Subtype B in North and South Americas and Europe, Subtype C in India, China and South Africa [4].

\section{Indian HIV Strains}

HIV molecular epidemiology studies carried out in different parts of India suggest that subtype $\mathrm{C}$ is the most prevalent among all HIV-1 genetic subtypes [20-23]. Sporadic presence of HIV-1 subtypes $\mathrm{A}$ and $\mathrm{B}$ has been reported in different parts of the country. Thai B subtype was shown to be circulating in North Eastern states, especially Manipur. However the proportion of Thai B subtype decreased over time among IDU's in Manipur. Thai B subtype was gradually replaced by Indian subtype C [23, 24].

Besides different subtypes, first recombinant $\mathrm{A} / \mathrm{C}$ mosaic virus was reported in India in 1998 [25]. The 
recombinant strains $\left(\mathrm{A} / \mathrm{C}, \mathrm{B}^{\prime} / \mathrm{C}\right)$ have since been reported from different parts of the country [4]. Although HIV-1 epidemic in India has spread to practically all states over last 20 years the Indian HIV-1 subtype $\mathrm{C}$ strains have shown a remarkable homogeneity. Analysis of HIV-1 subtype $\mathrm{C}$ genome sequences from India showed that these sequences were closely related to each other. These viruses are likely to be descendents of a single founder strain that was introduced in the beginning of the epidemic in India [26-28]. Lower genetic divergence has also been reported in other studies. It has been shown that the majority of Indian subtype $\mathrm{C}$ sequences cluster away from subtype $\mathrm{C}$ from other countries [27, 29-32].

The association of the genomic structure with the clinical presentation has been shown in a study conducted by Ranga et al. [33]. They have shown that the six amino acid residues are differentially conserved in subtype $\mathrm{C}$ Tat gene. Of these, cysteine (at position 31) was highly conserved (>99\%) in non-subtype C viruses while more than $90 \%$ of subtype $\mathrm{C}$ viruses show a serine substitution. The authors indicated, although not conclusively, that this mutation might be responsible for the lower incidence of HIV Associated Dementia (HAD) in India.

Only one study compared the viral fitness of strains of HIV-1 subtype $C$ and A from India. The in vitro replication fitness and transmission efficiency of primary isolates of HIV-1 subtypes $\mathrm{C}$ was higher than subtype A primary isolates [34]. This probably explains the predominance of subtype $\mathrm{C}$ strains in spite of introduction of subtype A strains in India more than decade and half ago.

\section{Pathogenesis of HIV Infection}

The natural course of HIV infection in India seems to be similar to the course described in other parts of the world; however, it has been shown that the Indian patients rapidly progress to the symptomatic disease after sero-conversion in a closely monitored cohort [35]. The observations from the same cohort described that fever, night sweats, and arthralgia as symptoms that may be predictive of recent HIV infection [36]. It has been observed that the patients with acute HIV infection in India showed plasma viral load values similar to those reported from the other parts of the world (unpublished observation). The observed median incubation period for progression from HIV infection to AIDS was 7.9 years, from AIDS Related Conditions (ARC) to AIDS was 1.9 years and the median survival time after developing AIDS was 19.2 months [37]. The data on natural history of HIV infection have shown that the disease progression is variable amongst the infected individuals. The viral and host factors play important role in the disease progression. Besides the innate immune responses and genetic factors the HIV-specific adaptive immune response has been shown to play very significant role in disease progression in HIV infection.

A case control study of 44 HIV seroconvertors and their matched HIV negative STD patient controls nested within the high risk STD cohort in Pune showed evidence of an independent association between low serum beta carotene levels and increased risk of heterosexual acquisition of HIV. The authors hypothesised that low vitamin $\mathrm{A}$ and carotenoid levels could increase risk by either altering the mucous membrane integrity or due to immunologic dysfunction [38]. The roles of other micronutrients in the disease progression have been studied across the world.

Hepatitis B and C (HBV and HCV) are very important co-infections that may influence the disease progression. The high risk HIV seronegative cohort at NARI revealed a high incidence of HBV (10.86 per 100 person years of follow up) [39]. Tattooing, history of being in commercial sex work and history of a genital ulcer were identified as being independently associated with a positive anti-HBc antibody test. These findings underline the need for Hepatitis $\mathrm{B}$ testing and vaccination programs among the most at risk populations (MARPs).

Although the evidence for sexual transmission of $\mathrm{HCV}$ is equivocal, HIV and HCV co-infections are more prevalent among IDUs with the primary driver being unsafe injecting practices. A study in Mizoram has identified prevalence of $\mathrm{HCV}$ antibodies in $71.2 \%$ HIV patients. A strong association was observed with the type of drugs injected $(p=0.001)$, frequency of injecting $(p=0.013)$, multiplicity of drugs used $(p=0.004)$, and needle syringe sharing $(p=0.003)$. There was no association with number of sexual partners or age at first sex or the type of sexual partners in the study [40].

\section{Innate Immune Response}

There is paucity of data on the innate immune response in India. Two studies published from India shed some light on the role of dendritic cells (DC) in HIV infection. Both studies have shown that the plasmacytoid dendritic cells (pDC) and myeloid dendritic cells (mDCs) were significantly reduced in HIV infection and correlated negatively with plasma viral load [41, 42]. Singh et al. have shown that there is irreversible loss of pDCs in early HIV infection and in AIDS stage. The loss of pDCs is primarily due to apoptosis. The decline seen in mDCs in AIDS stage appears primarily due to cell migration and is reversible on anti-retroviral treatment (ART). The decline in pDC numbers may be responsible for down regulation of innate immune responses. 


\section{Host Genetic Factors}

There is paucity of data on the genetic factors associated with HIV infection and disease progression. The Indian data has showed that in Western Indian population, $\mathrm{Cw}^{*} 1507, \mathrm{~B} * 3520$, and $\mathrm{B} * 1801$ class I HLA alleles and DRB $1 * 0902$-DQB $1 * 030103$ Class II alleles were significantly associated with HIV infection [43, 44]. Asian Indians have been reported to have extreme diversity in the MHC region, with several novel and unique alleles and disease-associated MHC haplotypes. CCR5 Delta 32 variant is rare and Indian population generally has low CCL3L1 copy numbers [45]. Systematic population based studies are needed to understand the impact of host genetics on HIV disease progression in India population.

\section{HIV-specific Immune Response in HIV Infected Indians}

HIV infection causes immune suppression as a result of the destruction of $\mathrm{CD} 4+\mathrm{T}$ lymphocytes that are central to immunoregulation. HIV infection causes the loss of CD4+ $\mathrm{T}$ cells, both HIV infected and HIV uninfected bystander cells. Immune activation has been considered to be the major cause of disease progression and $\mathrm{CD} 4+\mathrm{T}$ cell decline in HIV infected individuals.

Although HIV infection leads to the loss of CD4+ T cells and immune suppression, the host immune response may be critical for the control of viremia in HIV infected persons. Long term non-progressors (LTNPs), about 5\% among all HIV infected, show robust immune response and control virus multiplication successfully. Elite controllers are individuals who suppress plasma viremia completely in absence of anti-HIV treatment and present strong anti-HIV immune responses [46]. Hence the LTNPs and Elite controllers may provide clues about the immune mechanisms important for vaccine development.

Data on the immune response among Indian HIV patients is very limited.

\section{HIV-Specific Cytotoxic T Lymphocytes (CTL) response}

The HIV-specific CTL response has been shown to be important in controlling HIV multiplication [47, 48]. The studies on HIV-specific CTL response in Indian patients have reported Gag as most targeted antigen $[49,50]$. The epitopes recognized by Indian patients mainly resided within Gag (p17 and p24 region) and Nef region. Common immune-dominant regions were found to be recognized by the subtype $\mathrm{C}$ infected population from India, South Africa and Botswana. However, differential clustering of the immune-dominant region was also observed which may reflect differences in the circulating strains and class I HLA constitutions of the study population [51]. It is crucial that the studies are carried out with aim to identify the antigen/ epitopes that can induce robust and sustainable CTL response.

\section{Neutralizing Antibody Response}

The anti-HIV neutralizing antibody responses have been investigated in a small number of studies in India [52-54]. The results show that the neutralizing antibodies may appear early in HIV infections, but their significance in controlling early virus multiplication is not known [52]. Envelope structures from newly transmitted viruses in India are antigenically complex in spite of close genetic similarity. Delineation of neutralization cluster-associated amino acid signatures; 19 in gp120 and 14 in the ectodomain and cytoplasmic tail of gp41 provides a deeper understanding of the antigenic structure of HIV-1 envelop [53]. Another study estimated neutralizing antibody responses in asymptomatic HIV seropositives. Plasma samples from Indian HIV-1 infected persons were able to neutralize the autologous as well as other viruses isolated from different parts of India [54]. This observation may underline extensive sharing of neutralizing antibody determinants; thus providing a window of opportunity for immunological interventions such as vaccine. The antiHIV neutralizing antibodies are crucial in generating sterilizing immunity at the portal of entry of the HIV i.e., at the mucosal surface. Studies to identify the targets of neutralizing antibodies that are extensively cross-reactive may help in development of effective vaccine.

\section{Clinical Profile in Adult HIV Infected Individuals in India}

HIV infection passes through three stages of disease progression. The period immediately after acquiring HIV infection is an acute primary HIV infection that lasts for about 3-6 weeks and is also known as "Window period". Subsequently starts a long period of chronic disease that may last on an average for 7-10 years and the third stage of "AIDS" that may last for few years in absence of antiretroviral treatment. The opportunistic infections are notably seen during AIDS stage and less frequently during chronic stage of the infection.

Although HIV epidemic has progressed over last 25 years, there is no systematically collected data on the clinical presentations and natural history of HIV infection in India. The HIV epidemic in India is geographically diverse and there are regional differences, not only in the incidence and prevalence of HIV infection, but also in the 
Table 1 Profile of opportunistic infections in HIV infected individuals in India

\begin{tabular}{lll}
\hline Authors & Geographic location & Opportunistic Infections \\
\hline Kumarasamy et al. [93] & Chennai, South India & $\begin{array}{c}\text { Pulmonary tuberculosis, Pneumocystis jiroveci pneumonia, cryptococcal } \\
\text { meningitis, central nervous system toxoplasmosis }\end{array}$ \\
Vajpayee et al. [94] & Delhi, North India & $\begin{array}{l}\text { Tuberculosis, parasitic diarrhea and oral candidiasis } \\
\text { Singh et al. [95] }\end{array}$ \\
Manipal, South India & $\begin{array}{c}\text { Oral candidiasis, tuberculosis, Cryptosporidium infection and Pneumocystis } \\
\text { jiroveci pneumonia }\end{array}$ \\
Ghate et al. [96] & Pune, West India & Tuberculosis, cryptococcal meningitis, oral candidiasis, CMV retinitis \\
Charkravarty et al. [97] & Varanasi, Eastern India & Tuberculosis, oropharyngeal candidiasis, diarrhoea \\
Saldanha et al. [98] & Karnataka, South India & Tuberculosis, candidiasis, cryptosporidiosis and cryptococcal meningitis \\
Saha et al. [99] & Calcutta, North East India & Oral candidiasis, Cryptococcal diarrhoea, cytomegalovirus and Herpes \\
& & simplex virus-2
\end{tabular}

clinical presentations and profile of opportunistic infections (Table 1). However, pulmonary and extra-pumonary tuberculosis, oral candidiasis, cryptococcal meningitis and pneumocystis jiroveci pneumonia are some of the commonest occurring opportunistic infections. There is practically no data on the malignancies associated with HIV infection in Indian setting.

\section{HIV and HPV}

Studies among HIV infected women have shown that a significant proportion carry cervical precancerous lesions which can progress to invasive cancers if left undiagnosed and untreated [55].

A very high prevalence of high risk oncogenic HPV subtypes (16 \& 18) has been demonstrated in Pune (41.7\%) and Kolkata (32.2\%) among HIV infected women as compared to the uninfected. The morbidity due to anal HPV in MSM and the role of HPV in head neck cancers among the HIV infected persons are under study. Costeffective strategies for early diagnosis and intervention for pre-cancerous lesions need to be scaled up within the treatment and care programmes for HIV infected in India.

\section{Clinical Profile in HIV Infected Children}

The studies on clinical manifestations in HIV infected children have been carried out in various parts of the country. A study from Mumbai reported protein energy malnutrition, pulmonary and extra-pulmonary tuberculosis, hepato-splenomegaly, persistent generalized lymphadenopathy, chronic diarrhoea, oral thrush, pyrexia of unknown origin, chronic lung disease, chronic hypertrophic parotitis, chronic ottorrhea, recurrent lower respiratory tract infection, neurological manifestations and Pneumocystes jiroveci pneumonia in HIV infected children [56]. The common opportunistic infections observed in a study from Karnataka were tuberculosis, recurrent diarrhoea, oral candidiasis and recurrent bacterial pneumonia [57]. A recently published report from south India showed oral candidiasis, gingivitis, oral pigmentation, depapillation of the tongue, ulcers, and oral hairy leukoplakia in HIV infected children. The most common systemic lesion observed in this study was nonspecific lymphadenopathy followed by pruritic eruptions, measles, and tuberculosis [58].

\section{Diagnosis of HIV Infection}

Diagnosis of HIV infection can be carried out either by detecting antibodies to HIV antigens or p24 HIV antigen in serum or plasma or by demonstrating the HIV nucleic acid (DNA or RNA) in peripheral blood mononuclear cells or plasma. HIV antibody testing in serum/plasma using assays such as Enzyme Immuno Assays (EIAs) is the most commonly used method to diagnose HIV infection. HIV EIAs have become increasingly more sensitive and specific since HIV testing began in 1980s. The national guidelines in India recommends using three HIV antibody detecting tests with different HIV antigens / different principles in succession to confirm HIV infection. In case of discordance it is required to confirm HIV antibody status using a confirmatory test such as Western Blot or Line Immunoassay (LIA). In such situation it is mandatory that the test kits used as a first screening tests are very sensitive.

\section{HIV Diagnosis in Patients Within Window Period}

In case of the patients who have been infected recently and hence have not developed antibodies yet, the diagnosis of the HIV infection can be carried out using DNA PCR, or the quantitative HIV RNA PCR. P24 antigen detection can also be used in such cases. However, it is important to remember that the presence of p24 is transient and it may not be present in all patients with recent HIV infection. Hence the diagnostic utility of the p24 antigen detection is limited. 


\section{HIV Diagnosis in Infants and Children}

Diagnosis of HIV infection in babies born to HIV-infected mothers cannot be established by conventional antibody tests due to the presence of maternal anti-HIV antibodies in the circulation in child. These maternal antibodies may persist in the infant for as long as 18 months. Hence, HIV DNA-PCR or HIV RNA PCR is used for diagnosing HIV infection in children younger than 18 months. WHO recommends two positive HIV-1 DNA or RNA assay results at 6 weeks after birth (sensitivity $>98 \%$ ) for the definitive diagnosis of HIV-1 infection (WHO guideline). The whole blood sample is required for these assays; however some DNA and RNA PCR assays support the use of dried blood spot (DBS) samples, which have considerable advantages in settings where sample transportation and storage are a challenge. The National AIDS Control Program (NACP-III) has implemented the dried blood spots for DNA PCR testing in infants in 26 states under the government settings.

\section{External Quality Assurance}

It is extremely important to monitor the quality of the testing at every level. The testing laboratory must participate in the External Quality Assurance Scheme (EQAS) run by any external agency. The successful participation in the EQAS gives a confidence to the testing laboratories, offers trouble shooting and ensures generation of correct results. The National AIDS Control Organization (NACO) runs such EQAS programme for the laboratories under government programme through a network of laboratories with NARI as an apex laboratory.

\section{Monitoring of HIV Disease Progression}

The CD4+ T cell count is used as a marker of immunesuppression to decide when to initiate the antiretroviral therapy (ART), to monitor the success of ART and to decide when to initiate chemoprophylaxis for opportunistic infections. The plasma viral load estimation is the best indicator of how active HIV is in the patient's body, whereas the absolute CD4 cell count is more predictive of clinical disease progression. In the beginning of HIV epidemic, various other markers such as $\beta 2$ microglobulin, neopterin and various cytokines have been considered as the surrogate markers to monitor the disease progression [59-63]. Although nonspecific, these makers gave fairly good idea about the immune activation and thus the disease progression in HIV infected individuals.

\section{Anti Retroviral Treatment in India}

In early period of HIV epidemic in the country, a continuum of care for HIV/AIDS focused on medical care, counselling and psychosocial support. HIV/AIDS medical care included clinical examination, diagnosis \& treatment of opportunistic infections and referral of terminally ill patients to the tertiary care hospitals. CD4 count and viral load testing were unaffordable services for most HIV/AIDS patients and were done only at limited number of centres, such as research institutes and few private laboratories. Till 2003, it was estimated that out of 7,50,000 HIV infected individuals requiring ART, only $13,000(<2 \%)$ were on ART. A study from South India reported a dramatic decrease in mortality from 25 to 5 deaths per 100 person years of follow up in HIV infected individuals between 1997 and 2003 as a result of highly active antiretroviral treatment (HAART) [64].

Government of India (GOI) launched the free ART programme on 1st April 2004. The selection of first-line regimens under the programme is determined on the basis of a number of considerations, such as potency, profile of side-effects, ability to keep future treatment options open, adherence, cost, and potential of the development of resistant virus strains. The current global recommendation in all circumstances is a triple drug regimen. The key goals of the National ART programme include: providing longterm ART to eligible patients, monitoring and reporting treatment outcomes on a quarterly basis, attaining individual drug adherence rates of $95 \%$ or more, to increase life span so that $50 \%$ of patients on ART are alive 3 years after starting the treatment and to ensure that $50 \%$ of patients on ART are engaged in or can return to their previous employment. The programme has established 300 ART centres all over the country and 404882 PLHIV are

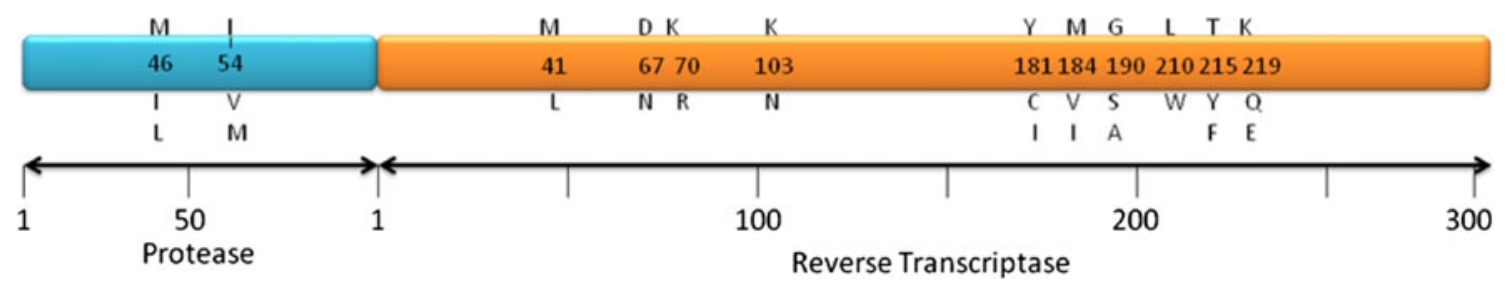

Fig. 4 Mutations in the HIV-1 protease and reverse transcriptase gene associated with drug resistance that are commonly found in Indian patients 
on ART by March 2011 [65]. The different studies done in India to evaluate the efficacy of the antiretroviral drugs in the programme have showed good clinical and immunological response to the therapy [66, 67].

The national programme currently provides antiretroviral drugs from nucleoside reverse transcriptase inhibitor (NRTI) and non nucleoside reverse transcriptase inhibitor (NNRTI) groups as first line treatment. It is a combination of two NRTIs (zidovudine or stavudine and lamivudine) and one NNRTI (nevirapine or efavirenz). Many countries in the world including India have accepted WHO recommendation of initiating ART when CD4 counts fall below 350 cells $/ \mathrm{cmm}$.

\section{Paediatric ART in India}

Studies carried out in children on generic antiretroviral drugs in private sector showed that HAART was effective and safe in paediatric population [68]. The Paediatric HIV care and treatment program was officially launched in November 2006. There was significant increase in the number of children registered in the ART clinics of which more than 18,000 children are receiving ART. The treatment guidelines that were developed jointly by the IAP, UNICEF, WHO and Clinton Foundation recommended the first line ART as a combination of stavudine, lamivudine and nevirapine. For children older than 3 years, who need both ART and therapy for tuberculosis, efavirenz is recommended instead of nevirapine [69].

It was seen from available data that nearly $2-3 \%$ patients on ART had developed treatment failure to the first line drugs as reported from a rapid survey of 38 ART centres conducted by World Health Organisation and National AIDS Control Organization in December 2006 [70]. Second-line ART was initiated using an approach combining clinical and immunologic evaluation with confirmation of virologic failure and it was reported that inclusion of targeted HIV RNA testing in the evaluation of treatment failure could prevent unnecessary switches to second-line ART [71].

\section{ARV Drug Resistance}

Antiretroviral drug resistance acts as a major impediment in the management of human immune deficiency virus type-1 (HIV-1) infection. The adherence to antiretroviral drugs becomes extremely important to prevent next epidemic of drug resistant HIV. The different studies in India have shown the resistance pattern to antiretroviral drugs [72] (Fig. 4).

National AIDS Research Institute in collaboration with NACO and WHO carried out two threshold surveillance surveys for drug resistance, among recently infected persons attending voluntary counselling and testing centre in Mumbai [72] and pregnant women in Kakinada, Andhra Pradesh [unpublished data]. The studies confirmed that the drug resistance mutations among recently transmitted virus strains were seen in less than $5 \%$ of isolates. In HIV drug resistance monitoring surveys conducted in two ART centres in Mumbai and Chennai under the same programme $10.3 \%$ and $7.4 \%$ respectively showed presence of drug resistance viruses at 12 months after initiation of ART under national ART programme [73]. This indicates that the current free ART regimen being provided by the GOI would be effective in majority of the subjects placed on the free ART regimen of National programme. But adherence remains the key issue for minimizing the drug resistance.

\section{HIV Prevention Efforts in India}

HIV prevention efforts in India have relied on risk reduction through Information, Education and Communication (IEC), interventions promoting behaviour change and condom use, prevention and treatment of sexually transmitted infections and encouraging Voluntary Counselling and Testing (VCT). The national programme lays emphasis on prevention of transfusion associated transmission and prevention of parent to child transmission (PPTCT) of HIV infection.

\section{Prevention of parent to Child transmission of HIV}

In the absence of any interventions, approximately 15-30\% of HIV infected pregnant women transmit HIV infection to the baby either ante-partum, during delivery or post-partum through breast milk. However, very effective interventions are available to prevent mother to child transmission. The program for Prevention of transmission from Parent to Child is a comprehensive program that focuses not only on

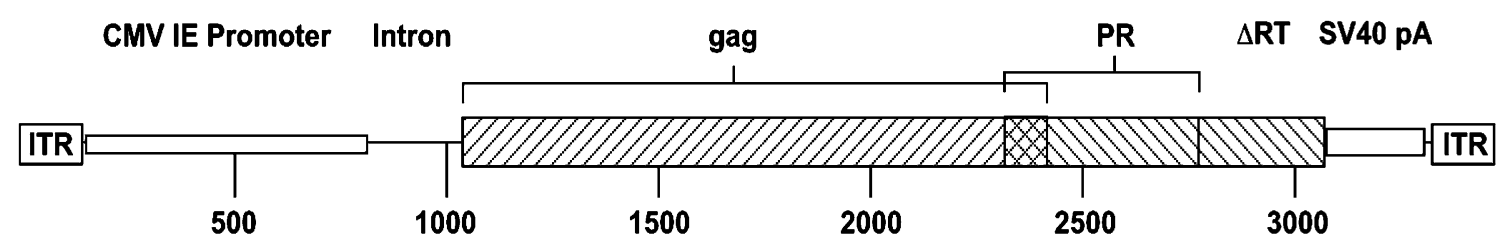

Fig. 5 Genetic structure of AAV2 (tgAAC09) candidate vaccine 
Fig. 6 HIV vaccine candidate used in the prime boost strategy in clinical trial in India
A DNA vaccine: ADVAX China HIV 1 subtype C/B'
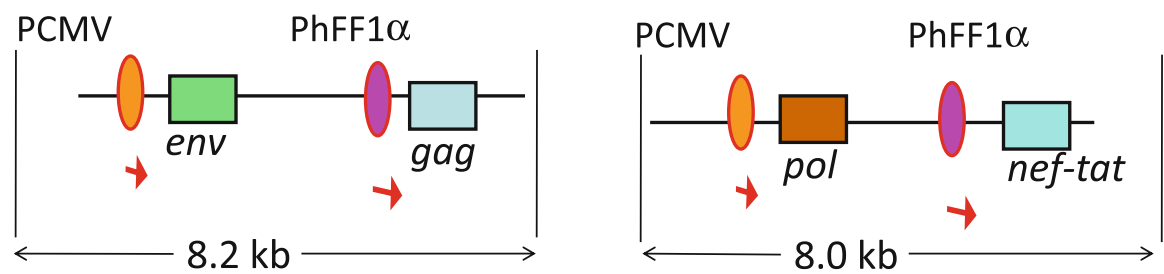

B MVA vaccine (TBC M4): Indian HIV 1 subtype C

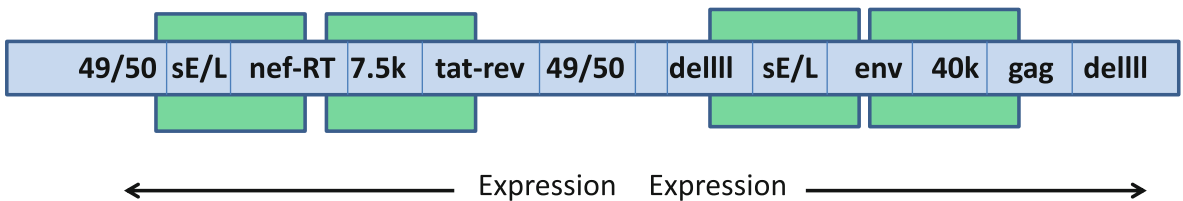

counselling, testing and prophylaxis intervention to prevent transmission from mother to child, it also encompasses the education of HIV negative mother, early diagnosis and linkage to care of the infants born to HIV infected mother linking the mother to care and support. Although this is one of the most effective interventions worldwide, there is a need to scale up the intervention. There is also a proposal to replace the current single dose nevirapine regimen with more potent triple drug combination. A study by NARI, B.J. Medical College Pune and Johns Hopkins University, Baltimore, USA has shown that the 6 weeks nevirapine prophylaxis given to the baby is safe and has greater efficacy compared to single dose nevirapine [74].

In spite of the progress achieved, only an estimated $20 \%$ of pregnant women in 2009 were counselled and tested and only $30 \%$ of the estimated $65,000 \mathrm{HIV}$ infected pregnant women could actually be reached [75], thus highlighting that even the best of intervention tools are limited by difficulties in implementation.

\section{Blood Safety}

Over last few years, the Blood Safety program has taken many steps to improve the quality of blood for transfusion, by introducing mandatory testing of blood and blood products for HIV, Hepatitis B \& C, Syphilis and Malaria. Current methods of donor screening and testing of donated blood have led to a decrease in the incidence of the transfusion-transmitted infections as well as HIV prevalence as reported by blood banks.

\section{HIV Vaccine Research}

While the national programme has relied on the risk reduction approach, a number of efforts are being made to apply newer prevention technologies like vaccines and microbicides for prevention of HIV infection.

A safe and effective vaccine has been the goal as well as the major challenge for HIV research worldwide. The preclinical studies on the development of HIV vaccine from India primarily showed the immunogenicity of the vector based vaccines (recombinant vaccinia expressing Indian HIV-1 subtype C Env or Gag proteins) in the Balb/C murine model $[76,77]$. Both the studies showed generation of HIV-specific humoral as well as cell mediated immune response as evaluated by IFN-gamma ELISPOT assay. Various vaccine candidates such as DNA vaccine expressing HIV-1 C Gag, the DNA vaccine expressing multiple CTL epitopes are being evaluated.

Three phase I human vaccine trials have been successfully conducted in India. The first Indian vaccine trial conducted at NARI Pune in 2005 was a dose escalation Phase I study using the Adeno-Associated Virus recombinant vaccine (tgAAC09) (Fig. 5) which expressed HIV-1 subtype $\mathrm{C}$ gag protease and RT genes; was found to be safe in humans but did not generate adequate immune response [78].

A recombinant Modified Vaccinia Ankara expressing env, gag, tat, rev, nef and $R T$ genes from Indian clade $\mathrm{C}$ virus (MVA-TBC M4) was developed under the Indian Council of Medical Research, NACO and International AIDS Vaccine Initiative collaborative vaccine programme. This vaccine underwent phase I human clinical trial at Tuberculosis Research Centre (TRC) in 2006. This vaccine was found to be safe and also able to elicit moderate immune response among the volunteers [79]. This vaccine was further tested in another trial using a prime and boost approach at both NARI and TRC using DNA vaccine (ADVAX) for priming and MVA-TBC M4 (Fig. 6a, b) for boosting. This heterologous strategy was compared with the 
homologous boosting using only MVA (TBC-M4). The study was completed in December 2010. Although final results are awaited there are indications that the prime-boost regime was safe and induced broader and stronger immune response [80]. The moderately successful Phase III vaccine trial (RV144) in Thailand showed that a prime boost combination was about $31 \%$ effective in modified intent to treat analysis for prevention of acquisition of HIV [81].

\section{Microbicides and Pre-Exposure Prophylaxis}

Encouraging evidences on efficacy of newer tools for prevention have emerged on the global horizon recently. A $1 \%$ gel formulation of tenofovir, anti-retroviral drug, as a vaginally applied microbicide showed $38 \%$ reduction of HIV incidence among women using the gel $50-80 \%$ of the times [82] and oral pre-exposure chemoprophylaxis using oral Tenofovir and Emtricitabine combination pill among men having sex with men [83] showed over 50\% protection. In India, where monogamous women continue to experience risk through the behaviours of their spouses, microbicides can be an important prevention tool, which will have to be scaled up along with behavioural interventions to empower women. Acceptability of women controlled prevention tools among both men and women is an important determinant that has been explored in India [84-86]. Indigenously developed microbicides like the Neem based 'Praneem' and curcumin based 'BASANT' have undergone early phase trials in India and many studies on acceptability of these and other microbicides have also been conducted [87-92].

India should be poised to accept and scale up newer preventive tools in a manner acceptable and feasible in our socio-cultural context in order to sustain and consolidate the gains that we have achieved so far.

Open Access This article is distributed under the terms of the Creative Commons Attribution License which permits any use, distribution, and reproduction in any medium, provided the original author(s) and the source are credited.

\section{References}

1. John TJ, Babu PG, Jayakumari H, Simoes EA (1987) Prevalence of HIV infection in risk groups in Tamilnadu, India. Lancet 1:160-161

2. Simoes EA, Babu PG, John TJ et al (1987) Evidence for HTLVIII infection in prostitutes in Tamil Nadu (India). Indian J Med Res 85:335-338

3. Godbole S, Mehendale S (2005) HIV/AIDS epidemic in India: risk factors, risk behaviour \& strategies for prevention \& control. Indian J Med Res 121:356-368

4. Lakhashe S, Thakar M, Godbole S, Tripathy S, Paranjape R (2008) HIV infection in India: epidemiology, molecular epidemiology and pathogenesis. J Biosci 33:515-525
5. Sarkar S, Das N, Panda S et al (1993) Rapid spread of HIV among injecting drug users in north-eastern states of India. Bull Narc 45:91-105

6. NACO press release: HIV declining in India; new infections reduced by $50 \%$ from 2000 to 2009 ; Sustained focus on prevention required, 1 Dec 2010. www.nacoonline.org/upload/HomePage/ NACO\%20PressreleaseonHIVestimate.pdf. Accessed 8 Dec 2011

7. Bachani D, Sogarwal R (2010) National response to HIV/AIDS in India. Indian J Community Med 35:469-472

8. Mehendale SM, Rodrigues JJ, Brookmeyer RS et al (1995) Incidence and predictors of human immunodeficiency virus type 1 seroconversion in patients attending sexually transmitted disease clinics in India. J Infect Dis 172:1486-1491

9. Gangakhedkar RR, Bentley ME, Divekar AD et al (1997) Spread of HIV infection in married monogamous women in India. Jama 278:2090-2092

10. Reynolds SJ, Risbud AR, Shepherd ME et al (2003) Recent herpes simplex virus type 2 infection and the risk of human immunodeficiency virus type 1 acquisition in India. J Infect Dis 187:1513-1521

11. Reynolds SJ, Risbud AR, Shepherd ME et al (2006) High rates of syphilis among STI patients are contributing to the spread of HIV-1 in India. Sex Transm Infect 82:121-126

12. Saggurti N, Verma RK, Jain A, Achyut P, Ramarao S (2008) Patterns and implications of male migration for HIV prevention strategies in Maharashtra, India. Technical brief from population Council India

13. Pandey A, Benara SK, Roy N et al (2008) Risk behaviour, sexually transmitted infections and HIV among long-distance truck drivers: across-sectional survey along national highways in India. Aids 22(Suppl 5):S81-S90

14. Paranjape RS, Tripathy SP, Menon PA et al (1997) Increasing trend of HIV seroprevalence among pulmonary tuberculosis patients in Pune, India. Indian J Med Res 106:207-211

15. Swaminathan S, Nagendran G (2008) HIV and tuberculosis in India. J Biosci 33:527-537

16. Swaminathan S, Ramachandran R, Baskaran G et al (2000) Risk of development of tuberculosis in HIV-infected patients. Int $\mathrm{J}$ Tuberc Lung Dis 4:839-844

17. Kulkarni S, Thakar M, Rodrigues J, Banerjee K (1992) HIV-2 antibodies in serum samples from Maharashtra state. Indian $\mathrm{J}$ Med Res 95:213-215

18. Babu PG, Saraswathi NK, Devapriya F, John TJ (1993) The detection of HIV-2 infection in southern India. Indian J Med Res 97:49-52

19. Chiara M, Rony Z, Homa M et al (2010) Characteristics, immunological response \& treatment outcomes of HIV-2 compared with HIV-1 \& dual infections (HIV 1/2) in Mumbai. Indian J Med Res 132:683-689

20. Soto-Ramirez LE, Tripathy S, Renjifo B, Essex M (1996) HIV-1 pol sequences from India fit distinct subtype pattern. J Acquir Immune Defic Syndr Hum Retrovirol 13:299-307

21. Gadkari DA, Moore D, Sheppard HW, Kulkarni SS, Mehendale SM, Bollinger RC (1998) Transmission of genetically diverse strains of HIV-1 in Pune, India. Indian J Med Res 107:1-9

22. Jameel S, Zafrullah M, Ahmad M, Kapoor GS, Sehgal S (1995) A genetic analysis of HIV-1 from Punjab, India reveals the presence of multiple variants. AIDS 9:685-690

23. Mandal D, Jana S, Bhattacharya SK, Chakrabarti S (2002) HIV type 1 subtypes circulating in eastern and northeastern regions of India. AIDS Res Hum Retroviruses 18:1219-1227

24. Chakrabarti S, Panda S, Chatterjee A et al (2000) HIV-1 subtypes in injecting drug users \& their non-injecting wives in Manipur, India. Indian J Med Res 111:189-194

25. Lole KS, Bollinger RC, Paranjape RS et al (1999) Full-length human immunodeficiency virus type 1 genomes from subtype 
C-infected seroconverters in India, with evidence of intersubtype recombination. J Virol 73:152-160

26. Novitsky VA, Montano MA, McLane MF et al (1999) Molecular cloning and phylogenetic analysis of human immunodeficiency virus type 1 subtype $\mathrm{C}$ : a set of 23 full-length clones from Botswana. J Virol 73:4427-4432

27. Shankarappa R, Chatterjee R, Learn GH et al (2001) Human immunodeficiency virus type 1 env sequences from Calcutta in eastern India: identification of features that distinguish subtype C sequences in India from other subtype C sequences. J Virol 75: 10479-10487

28. Novitsky V, Smith UR, Gilbert P et al (2002) Human immunodeficiency virus type 1 subtype $\mathrm{C}$ molecular phylogeny: consensus sequence for an AIDS vaccine design? J Virol 76: $5435-5451$

29. Agnihotri KD, Tripathy SP, Jere AP, Kale SM, Paranjape RS (2006) Molecular analysis of gp41 sequences of HIV type 1 subtype C from India. J Acquir Immune Defic Syndr 41:345-351

30. Kurle S, Tripathy S, Jadhav S, Agnihotri K, Paranjape R (2004) Full-length gag sequences of HIV type 1 subtype $\mathrm{C}$ recent seroconverters from Pune, India. AIDS Res Hum Retroviruses 20: $1113-1118$

31. Kalpana A, Srikanth T, Abhay J, Sushama J, Swarali K, Ramesh P (2004) gp120 sequences from HIV type 1 subtype C early seroconverters in India. AIDS Res Hum Retroviruses 20:889-894

32. Jere A, Tripathy S, Agnihotri K, Jadhav S, Paranjape R (2004) Genetic analysis of Indian HIV-1 nef: subtyping, variability and implications. Microbes Infect 6:279-289

33. Ranga U, Shankarappa R, Siddappa NB et al (2004) Tat protein of human immunodeficiency virus type 1 subtype $\mathrm{C}$ strains is a defective chemokine. J Virol 78:2586-2590

34. Rodriguez MA, Ding M, Ratner D et al (2009) High replication fitness and transmission efficiency of HIV-1 subtype $\mathrm{C}$ from India: implications for subtype $\mathrm{C}$ predominance. Virology 385 : 416-424

35. Mehendale SM, Bollinger RC, Kulkarni SS et al (2002) Rapid disease progression in human immunodeficiency virus type 1-infected seroconverters in India. AIDS Res Hum Retroviruses 18:1175-1179

36. Bollinger RC, Brookmeyer RS, Mehendale SM et al (1997) Risk factors and clinical presentation of acute primary HIV infection in India. Jama 278:2085-2089

37. Hira SK, Shroff HJ, Lanjewar DN, Dholkia YN, Bhatia VP, Dupont HL (2003) The natural history of human immunodeficiency virus infection among adults in Mumbai. Natl Med J India 16:126-131

38. Mehendale SM, Shepherd ME, Brookmeyer RS et al (2001) Low carotenoid concentration and the risk of HIV seroconversion in Pune, India. J Acquir Immune Defic Syndr 26:352-359

39. Risbud A, Mehendale S, Basu S et al (2002) Prevalence and incidence of hepatitis B virus infection in STD clinic attendees in Pune, India. Sex Transm Infect 78:169-173

40. Chelleng PK, Borkakoty BJ, Chetia M, Das HK, Mahanta J (2008) Risk of hepatitis C infection among injection drug users in Mizoram, India. Indian J Med Res 128:640-646

41. Mojumdar K, Vajpayee M, Chauhan NK, Mendiratta S, Wig N (2010) Defects in blood dendritic cell subsets in HIV-1 subtype c infected Indians. Indian J Med Res 132:318-327

42. Meera S, Madhuri T, Manisha G, Ramesh P (2010) Irreversible loss of pDCs by apoptosis during early HIV infection may be a critical determinant of immune dysfunction. Viral Immunol 23: 241-249

43. Shankarkumar U, Thakar M, Mehendale S, Praranjape RS, Mohanty D (2003) Association of HLA B*3520, B*1801, and Cw*1507 with HIV-1 infection Maharashtra, India. J Acquir Immune Defic Syndr 34:113-114
44. Shankarkumar U, Pawar A, Ghosh K, Bajpai S, Pazare A (2010) Human leucocyte antigen class II DRB1 and DQB1 associations in human immunodeficiency virus-infected patients of Mumbai, India. Int J Immunogenet 37:199-204

45. Kaur G, Mehra N (2009) Genetic determinants of HIV-1 infection and progression to AIDS: susceptibility to HIV infection. Tissue Antigens 73:289-301

46. Walker BD (2007) Elite control of HIV infection: implications for vaccines and treatment. Top HIV Med 15:134-136

47. Ogg GS, Kostense S, Klein MR et al (1999) Longitudinal phenotypic analysis of human immunodeficiency virus type 1-specific cytotoxic $\mathrm{T}$ lymphocytes: correlation with disease progression. J Virol 73:9153-9160

48. Cao J, McNevin J, Holte S, Fink L, Corey L, McElrath MJ (2003) Comprehensive analysis of human immunodeficiency virus type 1 (HIV-1)-specific gamma interferon-secreting CD8 $+\mathrm{T}$ cells in primary HIV-1 infection. J Virol 77:6867-6878

49. Thakar MR, Patke D, Lakhashe SK et al (2002) Consistent subtype-specific anti-HIV type $1 \mathrm{~T}$ lymphocyte responses in Indian subjects recently infected with HIV type 1. AIDS Res Hum Retroviruses 18:1389-1393

50. Kaushik S, Vajpayee M, Wig N, Seth P (2005) Characterization of HIV-1 Gag-specific T cell responses in chronically infected Indian population. Clin Exp Immunol 142:388-397

51. Thakar MR, Bhonge LS, Lakhashe SK et al (2005) Cytolytic T lymphocytes (CTLs) from HIV-1 subtype C-infected Indian patients recognize CTL epitopes from a conserved immunodominant region of HIV-1 Gag and Nef. J Infect Dis 192:749-759

52. Kulkarni S, Tripathy S, Gangakhedkar R et al (2008) Neutralizing antibody responses in recent seroconverters with HIV-1 subtype C infections in India. AIDS Res Hum Retroviruses 24:1159-1166

53. Kulkarni SS, Lapedes A, Tang H et al (2009) Highly complex neutralization determinants on a monophyletic lineage of newly transmitted subtype C HIV-1 Env clones from India. Virology 385:505-520

54. Lakhashe SK, Kulkarni SS, Thakar MR, Ghate MV, Paranjape RS (2007) Extensive cross-reactive neutralizing antibody response in Indian patients with limited genetic diversity of HIV1. Virology 359:295-301

55. Joshi SN, Gopalkrishna V, Kumar BK et al (2005) Cervical squamous intra-epithelial changes and human papillomavirus infection in women infected with human immunodeficiency virus in Pune, India. J Med Virol 76:470-475

56. Merchant RH, Oswal JS, Bhagwat RV, Karkare J (2001) Clinical profile of HIV infection. Indian Pediatr 38:239-246

57. Madhivanan P, Mothi SN, Kumarasamy N et al (2003) Clinical manifestations of HIV infected children. Indian J Pediatr 70: $615-620$

58. Ranganathan K, Geethalakshmi E, Krishna Mohan Rao U, Vidya KM, Kumarasamy N, Solomon S (2010) Orofacial and systemic manifestations in 212 paediatric HIV patients from Chennai, South India. Int J Paediatr Dent 20:276-282

59. Immanuel C, Victor L, Chelvi KS et al (2005) Serum neopterin levels in HIV infected patients with \& without tuberculosis. Indian J Med Res 121:220-225

60. Wanchu A, Arora S, Bhatnagar A, Sud A, Bambery P, Singh S (2004) Beta2 microglobulin as a surrogate marker for HIV infection: good correlation with CD4 counts. Indian J Pathol Microbiol 47:298-301

61. Thakar M, Rodrigues J, Athalye N, Banerjee K (1992) Serum beta 2 microglobulin levels in HIV seropositive persons. Indian J Med Res 95:168-170

62. Chaudhary M, Kashyap B, Gautam H, Saini S, Bhalla P (2008) Use of surrogate markers to predict the HIV disease stage and time to initiate antiretroviral therapy in developing countries. J Int Assoc Physicians AIDS Care (Chic) 7:259-264 
63. Kamat A, Ravi V, Desai A, Satishchandra P, Satish KS, Kumar M (2009) Estimation of virological and immunological parameters in subjects from South India infected with human immunodeficiency virus type 1 clade $\mathrm{C}$ and correlation of findings with occurrence of neurological disease. J Neurovirol 15:25-35

64. Kumarasamy N, Solomon S, Chaguturu SK et al (2005) The changing natural history of HIV disease: before and after the introduction of generic antiretroviral therapy in southern India. Clin Infect Dis 41:1525-1528

65. http://www.nacoonline.org/upload/Care\%20\&\%20Treatment/ NACO $\% 20$ guidelines $\% 20$ for $\% 20$ second $\% 20$ line $\% 20$ ART $\% 20$ April\%202011.pdf. Accessed 26 Dec 2011

66. Sharma SK, Dhooria S, Prasad KT et al (2010) Outcomes of antiretroviral therapy in a northern Indian urban clinic. Bull World Health Organ 88:222-226

67. Rajasekaran S, Jeyaseelan L, Raja K, Vijila S, Krithigaipriya KA, Kuralmozhi R (2009) Increase in CD4 cell counts between 2 and 3.5 years after initiation of antiretroviral therapy and determinants of CD4 progression in India. J Postgrad Med 55:261-266

68. Kumarasamy N, Venkatesh KK, Devaleenol B, Poongulali S, Mothi SN, Solomon S (2009) Safety, tolerability and effectiveness of generic HAART in HIV-infected children in South India. J Trop Pediatr 55:155-159

69. http://www.nacoonline.org/upload/Policies\%20\&\%20Guidelines/ $4 \% 20$ guidelines $\% 20$ for $\% 20 \mathrm{HIV} \% 20$ care $\% 20$ and $\% 20$ treatment $\%$ 20in\%20Infants\%20and\%20children.pdf. Accessed 26 Dec 2011

70. http://www.nacoonline.org/upload/Publication/Treatment $\% 20$ Care $\% 20$ and $\% 20$ support/Guidelines $\% 20$ for $\% 20$ HIV\%20care $\% 20$ and $\% 20$ treatment $\% 20 \mathrm{in} \% 20$ Infants $\% 20$ and $\% 20$ children.pdf. Accessed 17 Feb 2011

71. Rewari BB, Bachani D, Rajasekaran S, Deshpande A, Chan PL, Srikantiah P (2010) Evaluating patients for second-line antiretroviral therapy in India: the role of targeted viral load testing. J Acquir Immune Defic Syndr 55:610-614

72. Chaturbhuj DN, Hingankar NK, Srikantiah P et al (2010) Transmitted HIV drug resistance among HIV-infected voluntary counseling and testing centers (VCTC) clients in Mumbai, India. AIDS Res Hum Retroviruses 26:927-932

73. Hingankar N, Chaturbhuj D, Thorat S, Tripathy S, Rajasekaran S, Deshpande A, Srikantiah P, Reddy DCS, Garg R, Kabra S, Bachani D, Sujatha Rao K, Paranjape RS (2011) HIV drug resistance monitoring survey in India. US-INDIA Translational Research in HIV/AIDS in India (TRAI) conference, Goa

74. Six Week Extended-Dose Nevirapine (SWEN) Study Team, Bedri A, Gudetta B, Isehak A, Kumbi S, Lulseged S, Mengistu Y, Bhore AV, Bhosale R, Varadhrajan V, Gupte N, Sastry J, Suryavanshi N, Tripathy S, Mmiro F, Mubiru M, Onyango C, Taylor A, Musoke P, Nakabiito C, Abashawl A, Adamu R, Antelman G, Bollinger RC, Bright P, Chaudhary MA, Coberly J, Guay L, Fowler MG, Gupta A, Hassen E, Jackson JB, Moulton LH, Nayak U, Omer SB, Propper L, Ram M, Rexroad V, Ruff AJ, Shankar A, Zwerski S (2008) Extended-dose nevirapine to 6 weeks of age for infants to prevent HIV transmission via breastfeeding in Ethiopia, India, and Uganda: an analysis of three randomised controlled trials. Lancet 372(9635):300-313

75. Department of AIDS Control Annual report 2009-10 (2010)

76. Kumar S, Seth P (2004) Immunogenicity of recombinant Modified Vaccinia Ankara Viruses (rMVA) expressing HIV-1 Indian subtype $\mathrm{C}$ gag-protease and env-gp120 genes in mice. Viral Immunol 17:574-579

77. Shete A, Thakar M, Rajmane Y, Suregaonkar S, Tripathy S, Raut CG, Chakrabarti S, Paranjape R (2011) Vaccinia construct expressing gag gene from transmitted Indian HIV-1 subtype $\mathrm{C}$ strain induces cellular and humoral immune responses in BALB/c mice. J Glob Infect Dis 3(3):246-253
78. Mehendale S, van Lunzen J, Clumeck N et al (2008) A phase 1 study to evaluate the safety and immunogenicity of a recombinant HIV type 1 subtype $\mathrm{C}$ adeno-associated virus vaccine. AIDS Res Hum Retroviruses 24:873-880

79. Ramanathan VD, Kumar M, Mahalingam J et al (2009) A Phase 1 study to evaluate the safety and immunogenicity of a recombinant HIV type 1 subtype C-modified vaccinia Ankara virus vaccine candidate in Indian volunteers. AIDS Res Hum Retroviruses 25:1107-1116

80. VD Ramanathan SM, S Sahay, M Thakar, J Cox, G Stevens, P Chetty, J Gilmour, E Sayeed, L Dally, K Loughran, A Lombardo, J Ackland, M Krebs, S Kochhar, JL Excler, P Fast (2010) Safety and immunogenicity of DNA prime and modified vaccinia Ankara virus HIV subtype $\mathrm{C}$ vaccine boost in Indian volunteers. Abstract 2010; AIDS Vaccine Conference, Atlanta

81. Rerks-Ngarm S, Pitisuttithum P, Nitayaphan S et al (2009) Vaccination with ALVAC and AIDSVAX to prevent HIV-1 infection in Thailand. N Engl J Med 361:2209-2220

82. Abdool Karim Q, Abdool Karim SS, Frohlich JA et al (2010) Effectiveness and safety of tenofovir gel, an antiretroviral microbicide, for the prevention of HIV infection in women. Science 329:1168-1174

83. Grant RM, Lama JR, Anderson PL et al (2010) Preexposure chemoprophylaxis for HIV prevention in men who have sex with men. N Engl J Med 363:2587-2599

84. Joshi S, Kulkarni V, Paranjape R, Chandhiok N (2009) Challenges of introducing vaginal microbicides in India. Indian J Med Res 129:618-619

85. Tolley EE, Eng E, Kohli R et al (2006) Examining the context of microbicide acceptability among married women and men in India. Cult Health Sex 8:351-369

86. Marlowa HM, Tolley EE, Kohli R, Mehendale S (2010) Sexual communication among married couples in the context of a microbicide clinical trial and acceptability study in Pune India 2010. Cult Health Sex 2010:1-14

87. Joshi SN, Katti U, Godbole S et al (2005) Phase I safety study of Praneem polyherbal vaginal tablet use among HIV-uninfected women in Pune, India. Trans R Soc Trop Med Hyg 99: 769-774

88. Joshi SN, Dutta S, Kumar BK et al (2008) Expanded safety study of Praneem polyherbal vaginal tablet among HIV-uninfected women in Pune, India: a phase II clinical trial report. Sex Transm Infect 84:343-347

89. Talwar GP, Dar SA, Rai MK et al (2008) A novel polyherbal microbicide with inhibitory effect on bacterial, fungal and viral genital pathogens. Int J Antimicrob Agents 32:180-185

90. Bentley ME, Fullem AM, Tolley EE et al (2004) Acceptability of a microbicide among women and their partners in a 4-country phase I trial. Am J Public Health 94:1159-1164

91. Joglekar N, Joshi S, Kakde M et al (2007) Acceptability of PRO2000 vaginal gel among HIV un-infected women in Pune, India. AIDS Care 19:817-821

92. Joglekar NS, Joshi SN, Navlakha SN, Katti UR, Mehendale SM (2006) Acceptability of Praneem polyherbal vaginal tablet among HIV uninfected women \& their male partners in Pune, IndiaPhase I study. Indian J Med Res 123:547-552

93. Kumarasamy N, Solomon S, Flanigan TP, Hemalatha R, Thyagarajan SP, Mayer KH (2003) Natural history of human immunodeficiency virus disease in southern India. Clin Infect Dis 36:79-85

94. Vajpayee M, Kanswal S, Seth P, Wig N (2003) Spectrum of opportunistic infections and profile of CD4+ counts among AIDS patients in North India. Infection 31:336-340

95. Singh A, Bairy I, Shivananda PG (2003) Spectrum of opportunistic infections in AIDS cases. Indian J Med Sci 57:16-21 
96. Ghate MV, Tripathy SP, Kumar BK et al (2006) Rate of hospitalization and inpatient care costs for HIV-1-infected patients in Pune, India. Natl Med J India 19:10-14

97. Chakravarty J, Mehta H, Parekh A et al (2006) Study on clinicoepidemiological profile of HIV patients in eastern India. J Assoc Phys India 54:854-857
98. Saldanha D, Gupta N, Shenoy S, Saralaya V (2008) Prevalence of opportunistic infections in AIDS patients in Mangalore, Karnataka. Trop Doct 38:172-173

99. Saha K, Firdaus R, Santra P et al (2011) Recent pattern of Coinfection amongst HIV seropositive individuals in tertiary care hospital, Kolkata. Virol J 8:116 